Check for updates

Cite this: RSC Adv., 2018, 8, 5071

\title{
Probing the stereoselectivity of OleD-catalyzed glycosylation of cardiotonic steroids $\uparrow$
}

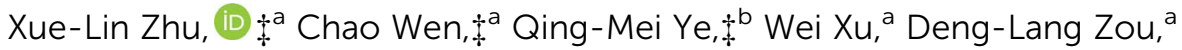 \\ Guang-Ping Liang, ${ }^{a}$ Fan Zhang, ${ }^{a}$ Wan-Na Chen ${ }^{a}$ and Ren-Wang Jiang ${ }^{\star a}$
}

The glycosyltransferase OleD variant as a catalyst for the glycosylation of four pairs of epimers of cardiotonic steroids (CTS) are assessed. The results of this study demonstrated that the OleD-catalyze glycosylation of CTS is significantly influenced by the configuration at C-3 and the A/B fusion mode. $3 \beta$ $\mathrm{OH}$ and $\mathrm{A} / \mathrm{B}$ ring cis fusion are favoured by OleD (ASP). An epoxide ring at C-14 and C-15 further increases the bioconversion rate; while an acetyl group at C-16 and lactone ring type at C-17 did not influence the biotransformation. A high conversion rate corresponded to a low $K_{m}$ value. A molecular docking simulation showed that filling of hydrophobic pocket II and interaction with residue Tyr115 may play an important role in the glycosylation reactions catalyzed by OleD glycosyltransferases. Furthermore, the glycosylation products showed a stronger inhibitory activity for $\mathrm{Na}^{+}, \mathrm{K}^{+}$-ATPase than the corresponding aglycones. This study provides the first stereoselective properties for OleD (ASP) catalyzed glycosylation.

Received 1st November 2017 Accepted 16th January 2018

DOI: $10.1039 / \mathrm{c} 7 \mathrm{ra11979h}$

rsc.li/rsc-advances

bufadienolides. Cardenolides, such as ouabain and digoxin,

\section{Introduction}

The glycosyltransferase OleD from Streptomyces antibioticus catalyzes the glycosylation of oleandomycin using UDP-Dglucose (UDPG) as the glycosyl donor. ${ }^{1-4}$ Recent studies revealed an enhanced triple mutant (A242V/S132F/P67T, OleD (ASP)) that displayed marked improvement in proficiency and substrate promiscuity. The OleD (ASP) was found to show highly permissive properties and is capable of glycosylation on 100 diverse acceptors, e.g. erythromycin, ${ }^{5}$ flavones, ${ }^{6}$ indole alkaloids ${ }^{7}$ and steroids. ${ }^{8}$ Nowadays, $56 \%$ of the drugs in clinics are chiral compounds; however $88 \%$ of them are marketed as racemates consisting of an equimolar mixture of two enantiomers. ${ }^{8}$ Although OleD (ASP) was found to catalyze the glycosylation of cardenolide and bufadienolide aglycone with a bias toward the desired C-3 regiospecificity, ${ }^{7}$ the stereospecificity of this enzyme remains unreported.

Cardiotonic steroids (CTS) ${ }^{9,10}$ such as digitoxin, digoxin and proscillaridin are clinically important drugs for treatment of congestive heart failure for more than two centuries due to their potent inhibition of $\mathrm{Na}^{+}, \mathrm{K}^{+}$-ATPase (NKA), which is an integral membrane protein maintaining ionic gradients in all superior eukaryotic cells. ${ }^{11-15}$ Natural CTS includes cardenolides and

\footnotetext{
${ }^{a}$ Guangdong Province Key Laboratory of Pharmacodynamic Constituents of TCM and New Drugs Research, College of Pharmacy, Jinan University, Guangzhou 510632, P. R. China.E-mail: trwjiang@jnu.edu.cn

${ }^{b}$ Department of Pharmacy, Hainan General Hospital, Haikou 570311, P. R. China $\dagger$ Electronic supplementary information (ESI) available: Spectroscopic data (NMR, MS) for compounds. See DOI: 10.1039/c7ra11979h

\$ These authors contribute equally to this work.
} possess a five-membered lactone ring at position C-17 $\beta$ of the steroidal skeleton. The natural cardenolide can be aglycone or glycosides with one or more sugar groups at C-3. ${ }^{16,17}$ Bufadienolides, isolated from many plants and animals such as Bufo bufo gargarizans, bears a six-membered lactone ring at C-17 $\beta$. The bufadienolides can also be aglycone or glycosides in plants but only aglycone in animals. ${ }^{18-21}$ For both bufadienolides and cardenolides, there is a hydroxy group at C-3, either $\beta$ - or $\alpha$ configuration. Normally the CTS with a $3 \beta-\mathrm{OH}$ shows more remarkable activities than the $3 \alpha$-diastereomer. ${ }^{22}$ Especially, the sugar groups of C-3 of CTS play a key role for the inhibitory activity of NKA. ${ }^{23}$

In this paper, we use OleD (ASP) to catalyze the glycosylation of four pairs of epimers of cardiotonic steroids. $K_{\mathrm{m}}$ values of two pairs of epimers representing the bufadienolides and cardenolides were determined. Molecular docking was used to simulate the interactions between the substrate and enzyme. Finally, the inhibitory activities against NKA of CTS aglycone and the corresponding glycosides were compared.

\section{Experimental section}

\section{General experimental procedures}

All chemicals and reagents were purchased from Sigma unless otherwise stated. The NMR spectra were recorded on a Bruker AV-400 spectrophotometer (Bruker, Germany) with TMS as internal standard. Chemical shifts $(\delta)$ were expressed in ppm with reference to the solvent signals. HR-ESI-MS were determined on a Micromass Q-TOF mass spectrometer (Waters, 
USA). Analytical HPLC is run on Agilent 1200 system (Agilent, USA) with a Phenomenex Luna C-18 column $(250 \mathrm{~mm} \times$ $4.6 \mathrm{~mm}, 5 \mu \mathrm{m}$, USA). Preparative HPLC was performed on a $\mathrm{Wu}$ Feng HPLC system (Shanghai, China) equipped with a preparative reverse phase column $(20 \times 250 \mathrm{~mm}, 5 \mu \mathrm{m})$.

\section{Cloning and expression of variant OleD (ASP) glycosyltransferase}

The OleD (ASP) glycosyltransferase gene was generated by Genscript Biotechnology (Nanjing, China) and was cloned into DH5 $\alpha$ (Takara, Japan) and pET28a (Novagen, USA) expression vector. Single colony of Escherichia coli BL21 (DE3) pLysS (Tiangen, China) transformed with pET28a/OleD vector was inoculated in Luria Bertani (LB) medium (3 mL) supplemented with $50 \mu \mathrm{g} \mathrm{mL}{ }^{-1}$ kanamycin. The medium was cultured overnight at $37^{\circ} \mathrm{C}$ with shaking $(200 \mathrm{rpm})$. The entire starter culture was then transferred to $1 \mathrm{~L}$ LB medium supplemented with $50 \mu \mathrm{g} \mathrm{mL} \mathrm{mL}^{-1}$ kanamycin and grown at $37{ }^{\circ} \mathrm{C}$ with shaking $(200 \mathrm{rpm})$ until the $\mathrm{OD}_{600}$ reached 0.6. Isopropyl $\beta$-D-thiogalactoside (IPTG) was subsequently added (final concentration to $0.4 \mathrm{mM}$ ) and the culture was incubated at $18{ }^{\circ} \mathrm{C}$ for $18 \mathrm{~h}$. Then the cell pellets were collected by centrifugation at $10000 \mathrm{~g}$ at $4{ }^{\circ} \mathrm{C}$ for $20 \mathrm{~min}$ and the supernatant was discarded. ${ }^{24}$ Pellets were resuspended in $10 \mathrm{~mL}$ PBS buffer (20 mM phosphate buffer, $0.2 \mathrm{M} \mathrm{NaCl}, 2 \mathrm{mM} \mathrm{KCl,} \mathrm{pH} \mathrm{7.4)} \mathrm{and}$ then lysed by sonication. Cell debris was removed by centrifugation at $10000 \mathrm{~g}$ at $4{ }^{\circ} \mathrm{C}$ for $20 \mathrm{~min}$ and the clear supernatant was immediately submitted to His60 Ni super flow resin (Clontech, USA). The resin was balanced by the equilibration buffer (50 mM sodium phosphate buffer, $0.3 \mathrm{M} \mathrm{NaCl}, 20 \mathrm{mM}$ imidazole, $\mathrm{pH}$ 7.4). The enzyme was allowed to bind for $1 \mathrm{~h}$ at $4{ }^{\circ} \mathrm{C}$ with gentle agitation, and the resin was washed with $10 \mathrm{~mL}$ mild buffer (20 mM phosphate buffer, $0.5 \mathrm{M} \mathrm{NaCl}, 50 \mathrm{mM}$ imidazole, pH 7.4). Finally, the protein was eluted by with $20 \mathrm{~mL}$ strong buffer (50 mM sodium phosphate buffer, $0.3 \mathrm{M} \mathrm{NaCl}$, $300 \mathrm{mM}$ imidazole, $\mathrm{pH}$ 7.4). The enzyme aliquots were immediately frozen in liquid nitrogen and stored at $-80{ }^{\circ} \mathrm{C}$. Protein purity was confirmed by SDS-PAGE to be $>95 \%$ and protein concentration for all studies was determined using the Bradford Protein Assay Kit from Bio-Rad (TransGen Biotech, China).

\section{Preparation of epimers of bufadienolides}

CTS (1 $\boldsymbol{\beta}, \mathbf{2} \boldsymbol{\beta}$ and $\mathbf{3} \boldsymbol{\beta}, 10.7 \mathrm{mM})$ was dissolved in $\mathrm{CH}_{2} \mathrm{Cl}_{2}(35 \mathrm{~mL})$ in a round bottom flask. Pyridinium chloride hydrochloride (PCC) (21.4 mM) was added and stirred constantly to dissolve. The solution was stirred for $2 \mathrm{~h}$ at room temperature. Then the solvent was removed under reduced pressure and the residue was dissolved in anhydrous tetrahydrofuran $(5 \mathrm{~mL})$ in a round bottom flask. Sodium borohydride $\left(\mathrm{NaBH}_{4}\right)$ was added and stirred constantly to dissolve. The solution was stirred for $1 \mathrm{~h}$ at room temperature. Then $5 \mathrm{~mL}$ of water was added slowly to the reaction solution. Ethyl acetate $(10 \mathrm{~mL})$ was used to extract the mixture and the solvent was removed under reduced pressure. The final residue was purified by preparative HPLC eluting with acetonitrile to yield C-3 $\alpha$ CTS $(1 \alpha, 2 \alpha, 3 \alpha)$.
1 $\alpha:{ }^{1} \mathrm{H}$ NMR $\left(\mathrm{CD}_{3} \mathrm{OD}, 400 \mathrm{MHz}\right) \delta: 8.01(1 \mathrm{H}, \mathrm{dd}, J=9.7$, $2.5 \mathrm{~Hz}, \mathrm{H}-22), 7.45(1 \mathrm{H}, \mathrm{d}, J=2.4 \mathrm{~Hz}, \mathrm{H}-21), 6.30$ (1H, d, $J=$ $9.8 \mathrm{~Hz}, \mathrm{H}-23), 3.58$ (1H, m, H-3), 2.58 (1H, m, H-17), 2.26-2.11 $(2 \mathrm{H}, \mathrm{m}), 1.92-1.62(11 \mathrm{H}, \mathrm{m}), 1.55-1.36(9 \mathrm{H}, \mathrm{m}), 1.29-1.19(1 \mathrm{H}$, m), 1.09-1.01 (2H, m), 0.95 (3H, s, H-19), 0.73 (3H, s, H-18); ${ }^{13} \mathrm{C}$ NMR ( $\left.\mathrm{CD}_{3} \mathrm{OD}, 100 \mathrm{MHz}\right) \delta: 164.8$ (C-24), 150.5 (C-21), 149.37 (C22), 125.0 (C-20), 115.4 (C-23), 86.1 (C-14), 72.3 (C-3), 52.3 (C-17), 49.8 (C-13), 43.2 (C-9), 43.1 (C-5), 41.9 (C-12), 37.7 (C-8), 37.0 (C4), 36.3 (C-1), 35.9 (C-10), 33.2 (C-15), 31.3 (C-2), 29.9 (C-16), 28.4 (C-6), 23.8 (C-19), 22.8 (C-7), 22.5 (C-11), 17.3 (C-18); HR-ESI-MS: $m / z$ 387.2576 [M + H $]^{+}$(calcd for $\mathrm{C}_{24} \mathrm{H}_{34} \mathrm{O}_{4}, 387.2534$ ).

2 $\alpha:{ }^{1} \mathrm{H}$ NMR $\left(\mathrm{CD}_{3} \mathrm{OD}, 400 \mathrm{MHz}\right) \delta: 7.91(1 \mathrm{H}, \mathrm{dd}, J=9.8$, $2.4 \mathrm{~Hz}, \mathrm{H}-22), 7.47(1 \mathrm{H}, \mathrm{d}, J=2.4 \mathrm{~Hz}, \mathrm{H}-21), 6.28(1 \mathrm{H} \mathrm{d}, J=$ $9.8 \mathrm{~Hz}, \mathrm{H}-23), 3.62$ (1H, s, H-15), 3.57 (1H, m, H-3), 2.61 (1H, d, J $=10.0 \mathrm{~Hz}, \mathrm{H}-10), 2.44(1 \mathrm{H}, \mathrm{d}, J=10.4 \mathrm{~Hz}, \mathrm{H}-16), 2.04-1.63(9 \mathrm{H}$, $\mathrm{m}), 1.63-1.28(9 \mathrm{H}, \mathrm{m}), 0.99(3 \mathrm{H}, \mathrm{s}), 0.79(3 \mathrm{H}, \mathrm{s}) ;{ }^{13} \mathrm{C} \mathrm{NMR}$ $\left(\mathrm{CD}_{3} \mathrm{OD}, 100 \mathrm{MHz}\right) \delta: 164.5$ (C-24), 151.8 (C-21), 149.6 (C-22), 124.5 (C-20), 115.3 (C-23), 75.8 (C-14), 72.2 (C-3), 61.1 (C-15), 48.6 (C-17), 46.3 (C-13), 43.1 (C-5), 41.3 (C-9), 40.1 (C-12), 36.9 (C-4), 36.1 (C-1), 36.0 (C-10), 35.2 (C-8), 33.2 (C-16), 31.3 (C-2), 27.5 (C-6), 23.8 (C-19), 22.1 (C-11), 22.0 (C-7), 17.1 (C-18); HRESI-MS: $m / z$ 385.2363 [M + H] $]^{+}$(calcd for $\mathrm{C}_{24} \mathrm{H}_{32} \mathrm{O}_{4}, 385.2407$ ).

$3 \alpha:{ }^{1} \mathrm{H}$ NMR $\left(\mathrm{CD}_{3} \mathrm{OD}, 400 \mathrm{MHz}\right) \delta: 8.04(1 \mathrm{H}, \mathrm{d}, J=9.6 \mathrm{~Hz}, \mathrm{H}-$ 22), 7.39 (1H, s, H-21), 6.26 (1H, d, $J=9.6 \mathrm{~Hz}, \mathrm{H}-23), 5.51(1 \mathrm{H}, \mathrm{d}$, $J=10.3 \mathrm{~Hz}, \mathrm{H}-16), 3.76(1 \mathrm{H}, \mathrm{s}, \mathrm{H}-15), 3.58$ (1H, m, H-3), $2.95(1 \mathrm{H}$, $\mathrm{d}, J=9.3 \mathrm{~Hz}, \mathrm{H}-17), 2.20-2.01(1 \mathrm{H}, \mathrm{td}, \mathrm{H}-8), 1.81\left(3 \mathrm{H}, \mathrm{s}, \mathrm{COCH}_{3}\right)$, 1.79-1.04 (15H, m), 0.99 (3H, s, H-19), 0.83 (3H, s, H-18); ${ }^{13} \mathrm{C}$ NMR ( $\left.\mathrm{CD}_{3} \mathrm{OD}, 100 \mathrm{MHz}\right) \delta: 171.6\left(\mathrm{COCH}_{3}\right), 164.0$ (C-24), 153.5 (C-22), 150.9 (C-21), 118.4 (C-20), 114.1 (C-23), 76.6 (C-16), 73.4 (C-14), 72.2 (C-3), 60.8 (C-15), 51.4 (C-17), 46.3 (C-13), 43.0 (C-5), 41.1 (C-9), 40.7 (C-12), 36.9 (C-4), 36.1 (C-1), 36.0 (C-10), 34.7 (C8), 31.2 (C-2), 27.4 (C-6), 23.7 (C-19), 21.9 (C-7), 21.9 (C-11), 20.4 $\left(\mathrm{COCH}_{3}\right), 17.5$ (C-18); HR-ESI-MS: $m / z$ 443.2445 [M + H] $]^{+}$(calcd for $\left.\mathrm{C}_{26} \mathrm{H}_{34} \mathrm{O}_{6}, 443.2314\right)$.

\section{General pilot-scale reaction}

In vitro glycosylation reactions were carried out in $500 \mu \mathrm{L}$ reaction buffer (50 mM Tris- $\mathrm{HCl}, \mathrm{pH} 8.0$ ) containing $250 \mu \mathrm{g}$ of enzyme, $2.5 \mathrm{mM}$ of UDPG, $1 \mathrm{mM}$ aglycon and $5 \mathrm{mM} \mathrm{MgCl}$. The mixture was incubated at $37^{\circ} \mathrm{C}$ for $16 \mathrm{~h}$. The reaction mixture was subsequently frozen and lyophilized, and the residue was resuspended in $500 \mu \mathrm{L}$ ice cold methanol and filtered. One portion of each clarified reaction mixture was analyzed by analytical reverse-phase HPLC equipped with a Phenomenex Luna-C18 column $(250 \mathrm{~mm} \times 4.6 \mathrm{~mm}, 5 \mu \mathrm{m})$. The flow rate was

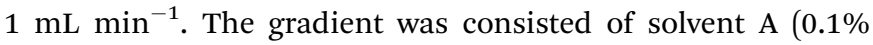
trifluoroacetic acid $/ \mathrm{H}_{2} \mathrm{O}$ ) and $\mathrm{B}$ (100\% acetonitrile): (a) 0$20 \mathrm{~min}, 10-75 \% \mathrm{~B}$; (b) 20-21 $\mathrm{min}, 75-100 \% \mathrm{~B}$; (c) 21-26 min, $100 \% \mathrm{~B}$; (d) 26-29 $\mathrm{min}, 100-10 \% \mathrm{~B}$; and (e) 29-35 min, 10\% B. Detections were set at 220 and $296 \mathrm{~nm}$. Conversion rate was calculated by the corresponding HPLC peak area percentage using the Agilent Chromatography Workstation Software. The LC-ESI-MS analysis was accomplished using standard C-18 reversed-phase chromatography with diode array detection wherein $5 \%$ of the flow was diverted to time-of-flight (TOF) mass spectrometer. 


\section{Preparative scale glycosylation reaction}

Aglycons (10 mg) were dissolved in 5\% of DMSO and transferred to $\mathrm{pH} 8$ buffer solution ( $50 \mathrm{mM}$ Tris- $\mathrm{HCl}, 5 \mathrm{mM} \mathrm{MgCl}$ ). UDPG was added followed by OleD (ASP) catalyst. After $16 \mathrm{~h}$ incubation at $37^{\circ} \mathrm{C}$, the reaction was stopped with equal volume of ice cold methanol. Then the reaction mixture was centrifuged at $10000 \mathrm{~g}$ for $30 \mathrm{~min}$ and the supernatant was concentrated under reduced pressure, and the debris was resuspended in $5 \mathrm{~mL}$ of ice-cold methanol and filtered with $0.22 \mu \mathrm{M}$ membrane. The filtrate was subjected to preparative HPLC $(20 \times 250 \mathrm{~mm}, 5 \mu \mathrm{m}$; flow rate: $5 \mathrm{~mL} \mathrm{~min}^{-1} ; A_{296}$ and $A_{220}$ detection) using water/ acetonitrile as the eluent to afford the corresponding of glucosides. The compound was then characterized using high resolution MS, ${ }^{1} \mathrm{D}$ and ${ }^{2} \mathrm{D}$ NMR, including ${ }^{1} \mathrm{H},{ }^{13} \mathrm{C}$ and HSQC.

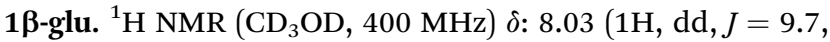
$2.3 \mathrm{~Hz}, \mathrm{H}-22), 7.45$ (1H, d, $J=1.8 \mathrm{~Hz}, \mathrm{H}-21), 6.30(1 \mathrm{H}, \mathrm{d}, J=$ 9.6 Hz, H-23), 4.37 (1H, d, $J=7.8 \mathrm{~Hz}$, sugar H-1), $4.12(1 \mathrm{H}, \mathrm{m}, \mathrm{H}-$ 3), $3.88(1 \mathrm{H}, \mathrm{d}, J=11.9,1.8 \mathrm{~Hz}), 3.71(1 \mathrm{H}, \mathrm{dd}, J=5.4 \mathrm{~Hz}), 3.40-$ 3.20 (4H, m), 2.56-2.52 (1H, m, H-17), 2.26-2.11 (2H, m), 1.92$1.22(23 \mathrm{H}, \mathrm{m}), 1.09-1.01(2 \mathrm{H}, \mathrm{m}), 0.95(3 \mathrm{H}, \mathrm{s}, \mathrm{H}-19), 0.73(3 \mathrm{H}, \mathrm{s}$, $\mathrm{H}-18) ;{ }^{13} \mathrm{C}$ NMR ( $\left.\mathrm{CD}_{3} \mathrm{OD}, 100 \mathrm{MHz}\right) \delta: 164.8$ (C-24), 150.5 (C-21), 149.37 (C-22), 125.0 (C-20), 115.4 (C-23), 102.7 (sugar C-1), 86.1 (C-14), 78.2 (sugar C-5), 77.84 (sugar C-2), 75.6 (sugar C-4), 75.2 (sugar C-3), 71.8 (C-3), 61.7 (sugar C-6), 52.3 (C-17), 49.8 (C-13), 43.2 (C-9), 43.1 (C-5), 41.9 (C-12), 37.7 (C-8), 37.0 (C-4), 36.3 (C1), 35.9 (C-10), 33.2 (C-15), 31.3 (C-2), 29.9 (C-16), 28.4 (C-6), 23.8 (C-19), 22.8 (C-7), 22.5 (C-11), 17.3 (C-18); HR-ESI-MS: m/z $549.3035[\mathrm{M}+\mathrm{H}]^{+}$(calcd for $\mathrm{C}_{30} \mathrm{H}_{44} \mathrm{O}_{9}, 549.3021$ ).

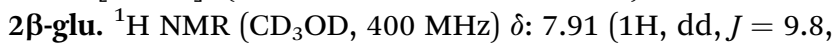
$2.4 \mathrm{~Hz}, \mathrm{H}-22), 7.46$ (1H, d, $J=2.4 \mathrm{~Hz}, \mathrm{H}-21), 6.27(1 \mathrm{H} \mathrm{d}, J=$ $9.8 \mathrm{~Hz}, \mathrm{H}-23), 4.32(1 \mathrm{H}, \mathrm{d}, J=7.8 \mathrm{~Hz}$, sugar H-1), $4.08(1 \mathrm{H}, \mathrm{m}, \mathrm{H}-$ 3), $3.86(1 \mathrm{H}, \mathrm{d}, J=11.9 \mathrm{~Hz}), 3.67(1 \mathrm{H}, \mathrm{dd}, J=11.9,5.4 \mathrm{~Hz}), 3.62$ (1H, s, H-15), 3.39-3.17 (7H, m), 2.61 (1H, d, J=10.0 Hz, H-10), 2.44 (1H, d, $J=10.4 \mathrm{~Hz}, \mathrm{H}-16), 2.04-1.43$ (15H, m), 1.40-1.05 $(4 \mathrm{H}, \mathrm{m}), 0.99(3 \mathrm{H}, \mathrm{s}), 0.79(3 \mathrm{H}, \mathrm{s}) ;{ }^{13} \mathrm{C} \mathrm{NMR}\left(\mathrm{CD}_{3} \mathrm{OD}, 100 \mathrm{MHz}\right) \delta$ : 164.5 (C-24), 151.8 (C-21), 149.6 (C-22), 124.5 (C-20), 115.3 (C23), 102.7 (sugar C-1), 78.2 (sugar C-5), 77.84 (sugar C-2), 75.8 (C-14), 75.4 (sugar C-4), 75.2 (sugar C-3), 71.7 (C-3), 62.8 (sugar C-6), 61.2 (C-15), 48.6 (C-17), 46.3 (C-13), 40.7 (C-12), 40.1 (C-9), 37.4 (C-10), 36.3 (C-5), 35.0 (C-4), 33.2 (C-8), 31.1 (C-1), 30.8 (C16), 27.5 (C-2), 27.0 (C-6), 24.1 (C-19), 22.2 (C-11), 21.7 (C-7), 17.2 (C-18); HR-ESI-MS: $m / z$ 547.2902 $[\mathrm{M}+\mathrm{H}]^{+}$(calcd for $\mathrm{C}_{30} \mathrm{H}_{42} \mathrm{O}_{9}$, 547.2938).

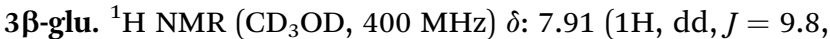
$2.4 \mathrm{~Hz}, \mathrm{H}-22), 7.47$ (1H, d, $J=2.4 \mathrm{~Hz}, \mathrm{H}-21), 6.28(1 \mathrm{H} \mathrm{d}, J=$ $9.8 \mathrm{~Hz}, \mathrm{H}-23), 4.34(1 \mathrm{H}, \mathrm{d}, J=7.8 \mathrm{~Hz}$, sugar H-1), $4.10(1 \mathrm{H}, \mathrm{m}, \mathrm{H}-$ 3), $3.87(1 \mathrm{H}, \mathrm{dd}, J=11.8,1.8 \mathrm{~Hz}), 3.76(1 \mathrm{H}, \mathrm{s}, \mathrm{H}-15), 3.69(1 \mathrm{H}$, $\mathrm{dd}, J=11.8,5.4 \mathrm{~Hz}$ ), 3.58 (1H, m, H-3), 3.45-3.17 (5H, m), 2.95 $(1 \mathrm{H}, \mathrm{d}, J=9.3 \mathrm{~Hz}, \mathrm{H}-17), 2.15-2.01(1 \mathrm{H}, \mathrm{td}, \mathrm{H}-8), 1.85(3 \mathrm{H}, \mathrm{s}$, $\left.\mathrm{COCH}_{3}\right), 1.81-1.04$ (19H, m), 0.99 (3H, s, H-19), 0.83 (3H, s, H$18) ;{ }^{13} \mathrm{C}$ NMR $\left(\mathrm{CD}_{3} \mathrm{OD}, 100 \mathrm{MHz}\right) \delta: 171.6\left(\mathrm{COCH}_{3}\right), 164.0(\mathrm{C}-$ 24), 153.5 (C-22), 150.9 (C-21), 118.4 (C-20), 114.1 (C-23), 102.7 (sugar C-1), 78.2 (sugar C-5), 77.84 (sugar C-2), 76.6 (C-16), 75.4 (sugar C-4), 75.2 (sugar C-3), 73.4 (C-14), 71.7 (C-3), 62.8 (sugar C-6), 60.8 (C-15), 51.4 (C-17), 46.3 (C-13), 40.5 (C-5), 40.7 (C-9), 37.3 (C-12), 36.3 (C-4), 36.1 (C-1), 36.0 (C-10), 31.7 (C-8), 31.2
(C-2), 27.4 (C-6), 23.7 (C-19), 21.9 (C-7), 21.9 (C-11), 20.4 $\left(\mathrm{COCH}_{3}\right), 17.5$ (C-18). HR-ESI-MS: $m / z$ 605.2996 [M + H $]^{+}$(calcd for $\left.\mathrm{C}_{32} \mathrm{H}_{44} \mathrm{O}_{11}, 605.2938\right)$.

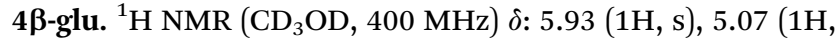
$\mathrm{d}, J=20,18.4 \mathrm{~Hz}), 4.95(1 \mathrm{H}, \mathrm{d}, J=19.8 \mathrm{~Hz}), 4.35(1 \mathrm{H}, \mathrm{d}, J=$ $7.8 \mathrm{~Hz}$, sugar H-1), 4.11 (1H, s, H-3), $3.89(1 \mathrm{H}, \mathrm{d}, J=2.1 \mathrm{~Hz}), 3.69$ (1H, dd, $J=11.8,5.4 \mathrm{~Hz}), 3.40-3.21(5 \mathrm{H}, \mathrm{m}), 2.95-2.79(1 \mathrm{H}, \mathrm{m})$, 2.35-2.12 (2H, m), 2.00-1.43 (19H, m), 1.40-1.22 (4H, m), 1.00 $(3 \mathrm{H}, \mathrm{s}), 0.92(3 \mathrm{H}, \mathrm{s}) ;{ }^{13} \mathrm{C}$ NMR $\left(\mathrm{CD}_{3} \mathrm{OD}, 100 \mathrm{MHz}\right) \delta: 178.5(\mathrm{C}-23)$, 177.3 (C-20), 117.8 (C-22), 102.7 (sugar C-1), 86.5 (C-14), 78.2 (sugar C-5), 77.8 (sugar C-2), 75.4 (sugar C-4), 75.3 (sugar C-3), 75.2 (C-31), 71.7 (C-3), 62.8 (sugar C-6), 52.2 (C-13), 51.1 (C17), 42.7 (C-9), 41.0 (C-8), 37.5 (C-5), 36.9 (C-12), 36.3 (C-10), 33.4 (C-4), 31.2 (C-15), 30.9 (C-1), 28.1 (C-2), 27.8 (C-6), 27.5 (C-16), 24.1 (C-7), 22.6 (C-7), 22.4 (C-18), 16.4 (C-19); HR-ESI-MS: $m / z 537.8049[\mathrm{M}+\mathrm{H}]^{+}$(calcd for $\mathrm{C}_{29} \mathrm{H}_{44} \mathrm{O}_{9}, 537.8021$ ).

\section{Determination of kinetic parameters}

Assays were performed in a final volume of $200 \mu \mathrm{L} 50 \mathrm{mM}$ Tris$\mathrm{HCl}$ ( $\mathrm{pH}$ 8.0), and contained constant concentrations of OleD (ASP) $(40 \mu \mathrm{g})$ and UDPG $(2.5 \mathrm{mM})$ while varying the concentration (0.01-1.2 mM) of $2 \beta, 2 \alpha, 4 \beta$ and $4 \alpha$. Aliquots $(100 \mu \mathrm{L})$ were removed every $15 \mathrm{~min}$, mixed with an equal volume of ice cold methanol, and centrifuged at $10000 \mathrm{~g}$ for $10 \mathrm{~min}$. Supernatants were analyzed by analytical reverse-phase HPLC. Conversion rate is calculated by the corresponding HPLC peak area percentage using the Agilent Chromatography Workstation Software. ${ }^{25}$ All experiments were performed in triplicate. Initial velocities were fitted to the Michaelis-Menten equation using Origin Pro 7.0 software.

\section{Molecular docking}

The program Autodock Vina was used for docking simulations. For docking purpose, the crystal structure of OleD (PDBID 4M60) was retrieved from Protein Data Bank. To create receptor and ligand structures for docking, the following procedure was conducted. Firstly, the 3D structures of the ligands were prepared using the Gaussian 09 program at the B3LYP/6-31G(d) level. Harmonic vibration frequencies were calculated to confirm the stability of these conformers. Then the receptor and optimized structure of the ligands were converted to required pdbqt format using Autodock Tools 1.5.4. The Autodock Vina parameters were set as follow, box size: $15 \times 15 \times 15 \AA$, the center of box: $x=38.96, y=61.05, z=13.83$, the exhaustiveness: 100 , and number of output conformations was set to 20 . The calculated geometries were ranked in terms of free energy of binding and the best poses were selected for further analysis. All molecular visualizations were carried out in PyMOL software.

\section{Assessment inhibition NKA activity of CTS}

The inhibitory effects of CTS on NKA were determined essentially as previously reported method.11,26,27 


\section{Results and discussion}

\section{Preparation of epimers of bufadienolides}

Three epimers, i.e. $\alpha$-bufalin $(\mathbf{1} \alpha), \alpha$-resibufogenin $(\mathbf{2} \alpha)$ and $\alpha$ cinobufagin $(3 \alpha)$ were synthesized from $\beta$-bufalin $(\mathbf{1} \beta), \beta$-resibufogenin (3⿻) and $\beta$-cinobufagin $(3 \boldsymbol{\beta})$, respectively, by an oxidation with pyridinium chloride hydrochloride followed by a reduction with sodium borohydride. Uzarigenin $(\mathbf{4} \alpha)$ and digitoxigenin (4及), two natural cardenolides with a trans and cis A/B fusion mode ( $4 \alpha, 4 \boldsymbol{\beta}$ Fig. 1), respectively, were identified from the whole herb of Asclepias curassavica ${ }^{28}$ and the roots of Streptocaulon juventas, ${ }^{29}$ respectively. These probes are suitable for us to investigate whether the configurations at C-3 and the fusion mode of $\mathrm{A} / \mathrm{B}$ ring influence the OleD-catalyze glycosylation.

\section{Glycosylation of $1 \beta$ and $1 \alpha$}

Both $3 \alpha$ - and $3 \beta$-hydroxylated bufalin are endogenous in Bufo bufo gargarizans. Though only $3 \beta$-hydroxylated bufalin is present as a toxic chemical defence in toad venom, both epimers were found to occur at a $2: 3$ ratio in the heart and a $1: 2$ ratio in the blood. ${ }^{22} 3 \beta$-Hydroxylated bufalin is the major active component of the toad venom and exhibits potent cardiotonic activity. ${ }^{30,31}$ Its structural core includes a cis-transcis fused steroid core with two hydroxyl groups at C-3 and C-14.

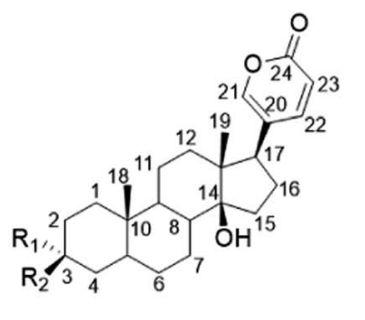

$\begin{array}{lll}\mathbf{1} \boldsymbol{1} & \mathrm{R}_{1}=\mathrm{OH} & \mathrm{R}_{2}=\mathrm{H} \\ \mathbf{1} \boldsymbol{-} \text {-glu } & \mathrm{R}_{1}=\mathrm{OH} & \mathrm{R}_{2}=\mathrm{O}-\boldsymbol{\beta}-\mathrm{D} \text {-glu } \\ \mathbf{1} \boldsymbol{\beta} & \mathrm{R}_{1}=\mathrm{H} & \mathrm{R}_{2}=\mathrm{OH} \\ \mathbf{1} \boldsymbol{\beta} \text {-glu } & \mathrm{R}_{1}=\mathrm{H} & \mathrm{R}_{2}=\mathrm{O}-\boldsymbol{\beta} \text {-D-glu }\end{array}$

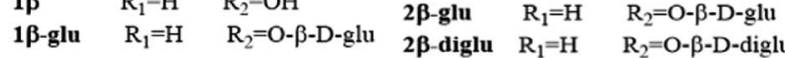

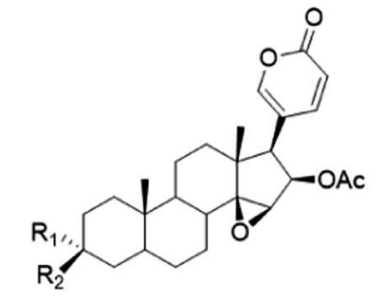

$3 \alpha \quad \mathrm{R}_{1}=\mathrm{OH} \quad \mathrm{R}_{2}=\mathrm{H}$

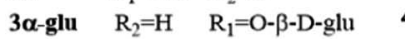

$3 \beta \quad \mathrm{R}_{1}=\mathrm{H} \quad \mathrm{R}_{2}=\mathrm{OH} \quad 4 \alpha$-glu $\quad \mathrm{R}_{1}=\alpha-\mathrm{H} \quad \mathrm{R}_{2}=\mathrm{O}-\beta$-D-glu

3/-glu $\quad \mathrm{R}_{1}=\mathrm{H} \quad \mathrm{R}_{2}=\mathrm{O}-\beta$-D-glu $\quad 4 \beta \quad \mathrm{R}_{1}=\beta-\mathrm{H} \quad \mathrm{R}_{2}=\mathrm{OH}$

3/-diglu $\quad R_{1}=H \quad R_{2}=O-\beta$-D-diglu $\quad 4 \beta$-glu $\quad R_{1}=\beta-H \quad R_{2}=O-\beta$ - $D$-glu

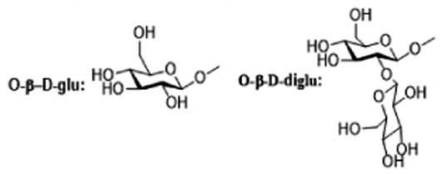

Fig. 1 Structures of cardiotonic steroid substrates and the corresponding glycosylation products.
However, it has serious toxicity because there is no distinct selectivity for $\alpha 1$ and $\alpha 2$ subunits of NKA. Fortunately, a lot of bufalin analogues including glycosides have been prepared by chemical and biological transformation. Recently, our group reported synthesis of $3 \beta-N$-methoxy- $N$ - $\beta$-D-glucoside of bufalin which could enhance its inhibition on NKA. ${ }^{22}$ The latest crystal structure demonstrated that the level of glycosylation affect the depth of CTS binding and that the steroid core substituents fine tune the configuration of transmembrane helices $\alpha \mathrm{M} 1-2 .^{27}$ Furthermore, the sugar unit could enhance the selectivity on the alpha2 isoform of NKA; however, chemical synthesis of bufalin glycoside was laborious and consumed a lot of toxic reagents. It is necessary to develop a green method for glycosylation of bufadienolides.

The pilot biotransformation of $\mathbf{1 \beta}$ and $\mathbf{1} \alpha$ were carried out using UDPG as the sugar donor and OleD (ASP) as the catalyst under the standard conditions (0.5 mM UDPG, 0.1 mM aglycon, $16 \mathrm{~h}){ }^{5}$ The result of LC-MS showed that OleD (ASP) could catalyze the generation of monoglycoside of $\mathbf{1} \boldsymbol{\beta}$ with a conversion rate $30 \%$; while glycosylation product of $1 \alpha$ was not detected (Fig. 2). Thus the bioconversion of $\mathbf{1} \boldsymbol{\beta}$ and $\mathbf{1} \alpha$ catalyzed by OleD (ASP) was influenced by the C-3 configuration. The conversion rates of different isomers were compared in Table 1.

To maximize the production of bufalin-3-O- $\beta$-D-glucoside (1及-glu), a $20 \mathrm{~h}$ reaction was carried out at $37^{\circ} \mathrm{C}$. Compound $\mathbf{1 \beta}$ (10 mg, $40 \mathrm{mM})$ was dissolved in DMSO $(0.625 \mathrm{~mL})$ and diluted with buffer solution (50 mM Tris- $\mathrm{HCl}, 5 \mathrm{mM} \mathrm{MgCl}_{2}, \mathrm{pH} 8.0$, $25 \mathrm{~mL}$ total volume). UDPG (38 $\mathrm{mg}, 50 \mathrm{mM}$ ) was added along with OleD (ASP) (13 mg). The reaction was stopped with $25 \mathrm{~mL}$ of ice cold methanol. Then the reaction mixture was centrifuged at $10000 \mathrm{~g}$ for $30 \mathrm{~min}$ and supernatant was concentrated under reduced pressure. The residue was dissolved in $3 \mathrm{~mL}$ methanol, and filtered with $0.22 \mu \mathrm{M}$ membrane. The filtrate was subjected to preparative HPLC using water/acetonitrile as the eluent.
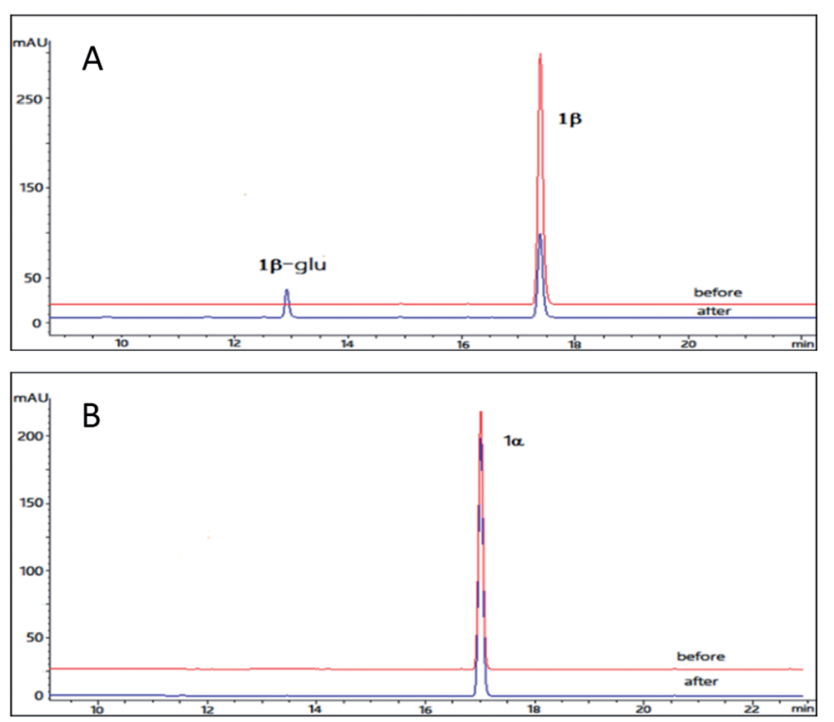

Fig. 2 HPLC chromatograms of the enzymatic reactions. (A) $1 \boldsymbol{\beta}$ without UDPG and OleD (ASP) (before); $1 \beta$ with UDPG and OleD (ASP) (after); (B) $1 \alpha$ without UDPG and OleD (ASP) (before) (1); $1 \alpha$ with UDPG and OleD (ASP) (after). 
Table 1 Conversion rates of individual compounds

\begin{tabular}{|c|c|c|}
\hline Compounds & Products & Conversion rate $(\%)$ \\
\hline $1 \alpha$ & $1 \alpha-$ glu & N. $\mathrm{T}^{a}$ \\
\hline $1 \beta$ & $1 \beta$-glu & 30 \\
\hline $2 \alpha$ & $2 \alpha$-glu & 1 \\
\hline \multirow[t]{2}{*}{$2 \beta$} & $2 \beta$-diglu & 1 \\
\hline & $2 \beta$-glu & 79 \\
\hline $3 \alpha$ & $3 \alpha$-glu & 2 \\
\hline \multirow[t]{2}{*}{$3 \beta$} & 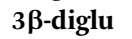 & 5 \\
\hline & $3 \beta$-glu & 70 \\
\hline $4 \alpha$ & $4 \alpha$-glu & 2 \\
\hline $4 \beta$ & $4 \beta$-glu & 25 \\
\hline
\end{tabular}

Finally, $3.1 \mathrm{mg}$ of $\mathbf{1} \boldsymbol{\beta}$-glu was obtained with a conversion rate of $21 \%$. The structure of $\mathbf{1 \beta}$-glu was determined by ${ }^{1} \mathrm{D}$ NMR and HR-ESI-MS analysis. The pseudo molecular ion $m / z$ 549.3035 [M $+\mathrm{H}]^{+}$in the HR-ESI-MS was corresponding to a formula $\mathrm{C}_{30} \mathrm{H}_{44} \mathrm{O}_{9}$ (calcd for 549.3021), which was 162 unit larger than the parent compound bufalin, suggesting the formation of monoglucoside. Compared with $\mathbf{1} \boldsymbol{\beta}$, the chemical shift $\delta_{\mathrm{C}-3}$ of $\mathbf{1 \beta}$-glu was shifted to downfield by $3.9 \mathrm{ppm}$ and the $\delta_{\mathrm{H}-3}$ was shifted to downfield by $0.02 \mathrm{ppm}$; while C-14 was unchanged, confirming the glycosylation site was at $3-\mathrm{OH}$. The $\beta$-configuration was determined by the large coupling constant of the anomeric proton $\left(\delta_{\mathrm{H}} 4.37, \mathrm{~d}, J=7.8 \mathrm{~Hz}\right)$. Based on the above analysis, it was concluded that OleD (ASP) could catalyze the transformation of $\mathbf{1} \boldsymbol{\beta}$ to its monoglucoside $\mathbf{1} \boldsymbol{\beta}$-glu at $3-\mathrm{OH}$.

\section{Glycosylation of $2 \beta$ and $2 \alpha$}

Resibufogenin (2 $\boldsymbol{\beta})$ is another type of bufadienolides from the venom of Bufo bufo gargarizans with an 14,15-epoxide ring in contrast to the $14-\mathrm{OH}$ in bufalin. Compound $2 \boldsymbol{\beta}$ has been reported to exhibit a wide range of activities such as cardiotonic, renal sodium excretion, blood pressure stimulating, antitumor activity and immunoregulatory activity. ${ }^{32}$ However, the application of resibufogenin is restricted because of its strong toxicity. ${ }^{33}$ In the past several years, several structure modifications on $2 \boldsymbol{\beta}$ was performed which generate more than 30 derivatives. ${ }^{23}$ In order to obtain the glycosylation derivative of $2 \boldsymbol{\beta}$ and compare the NKA inhibitory activities of these derivatives with different configurations, OleD (ASP) catalysed biotransformation on $2 \boldsymbol{\beta}$ and $2 \alpha$ were carried out.

The pilot reaction conditions are the same as those described for $\mathbf{1} \boldsymbol{\beta}$ and $\mathbf{1} \boldsymbol{\alpha}$. According to the result of LC-MS analysis, OleD (ASP) catalyzed the formation of monoglucoside (major) and diglucoside (minor) of $\mathbf{2} \boldsymbol{\beta}$ with a total conversion rate $80 \%$ which was much higher than that of $\mathbf{1} \boldsymbol{\beta}$; while the conversion rate of monoglucoside $2 \alpha$-glu is about $1 \%$ in contrast to the absence of $1 \alpha$ glucoside (Fig. 3). Thus similar to $\mathbf{1} \boldsymbol{\beta}$ and $1 \alpha$, the configuration at C-3 was also important for conversion rate of $2 \boldsymbol{\beta}$ and $2 \boldsymbol{\alpha}$. The much high conversion rate of $2 \beta$ and $2 \alpha$ might be due to the 14,15-epoxide moiety as compared to the $14-\mathrm{OH}$ for $1 \beta$ and $1 \alpha$.
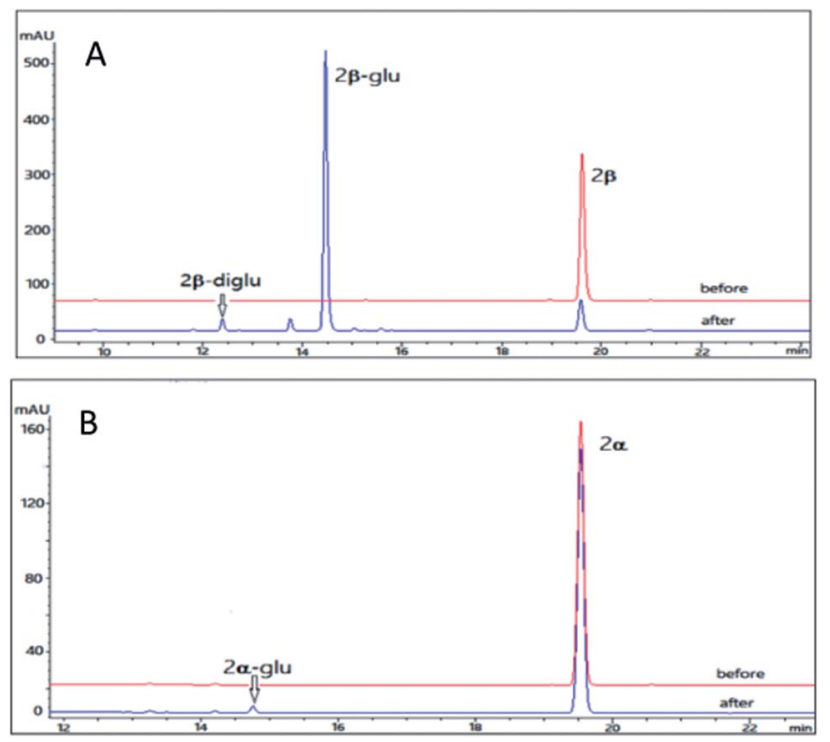

Fig. 3 HPLC chromatograms of the enzymatic reactions. (A) $2 \boldsymbol{\beta}$ without UDPG and OleD (ASP) (before); $2 \boldsymbol{\beta}$ with UDPG and OleD (ASP) (after); (B) $2 \alpha$ without UDPG and OleD (ASP) (before); $2 \alpha$ with UDPG and OleD (ASP) (after).

To maximize the production of resibufogenin-3- $O-\beta-\mathrm{D}-$ glucoside (2 $\beta$-glu), a preparative scale experiment was undertaken. Using the same condition as $\mathbf{1} \boldsymbol{\beta}$, while $2 \boldsymbol{\beta}(10 \mathrm{mg}, 40 \mathrm{mM})$ was served as substrate, we obtain $8.4 \mathrm{mg} 2 \boldsymbol{2}$-glu with a conversion rate $65 \%$. The identification of compounds $2 \beta$-glu was determined by ${ }^{1} \mathrm{D}$ NMR and HR-ESI-MS analysis. The pseudo-molecular ion $m / z 547.2902[\mathrm{M}+\mathrm{H}]^{+}$in the HR-ESI-MS corresponded to a formula $\mathrm{C}_{30} \mathrm{H}_{42} \mathrm{O}_{9}$ (calcd for 547.2938) which was 162 unit larger than the parent compound $\mathbf{2} \boldsymbol{\beta}$. Compared with $\mathbf{2} \boldsymbol{\beta}$, the chemical shift C-3 of $\mathbf{2} \boldsymbol{\beta}$-glu was shifted to downfield by $3.9 \mathrm{ppm}$ and the chemical shift $\mathrm{H}-3$ was shifted to downfield by $0.02 \mathrm{ppm}$, confirming the glycosylation site was also at 3-OH. The $\beta$-configuration was determined by the large coupling constant of the anomeric proton $\left(\delta_{\mathrm{H}} 4.32, \mathrm{~d}\right.$, $J=7.8 \mathrm{~Hz}$ ). Accordingly, it was concluded that OleD (ASP) could catalyze the transformation of $2 \boldsymbol{\beta}$ to its glucoside $2 \boldsymbol{\beta}$-glu with a much higher rate than $\mathbf{1 \beta}$. It is noteworthy that bioconversion of $2 \boldsymbol{\beta}$ also lead to the generation of a diglucoside (2 $\boldsymbol{\beta}$-diglu) which was confirm by the HR-MS $m / z 709.3421[\mathrm{M}+\mathrm{H}]^{+}$. Due to the small amount, it was not determined by NMR.

\section{Glycosylation of $3 \beta$ and $3 \alpha$}

Cinobufagin is also a major bufadienolides (4-6\% dry weight) from the venom of Bufo bufo gargarizans with an 14,15-epoxide ring and an acetyl group at $\mathrm{C}-16 .{ }^{34}$ Cinobufagin was found to show potent cardiotonic, blood pressure-stimulating, antiviral, local anesthetic and antineoplastic activities. ${ }^{34,35}$ However, the poor water solubility restricted its clinical use. Though a series of analogues of cinobufagin has been generated by chemical synthesis and cell suspension cultures, ${ }^{33,36}$ the glycosylation method is rarely reported. Furthermore, difference between the glycosidation profile on the $\mathbf{3} \boldsymbol{\beta}$ and $\mathbf{3} \boldsymbol{\alpha}$ isomers of cinobufagin is unclear. 
Using the same reaction conditions as described for $2 \boldsymbol{\beta}$ and $2 \alpha$, OleD (ASP) was found to catalyze the glycosylation of $3 \beta$ leading to both monoglucoside ( $3 \beta$-glu) and diglucoside ( $3 \beta$ diglu) of $3 \boldsymbol{\beta}$ with a total conversion rate of $75 \%$; while at the same condition as $\mathbf{3} \boldsymbol{\beta}$, only the monoglucoside of ( $\mathbf{3} \boldsymbol{\alpha}$-glu) was detected with a low conversion rate $2 \%$ (Fig. 4). Similarly, this phenomenon further confirmed the importance of configuration at C-3 for the conversion rate. It is noteworthy that with an additional acetyl group at $\mathrm{C}-16$ compound $\mathbf{3} \boldsymbol{\beta}$ showed similar conversion rate as $\mathbf{2 \beta}$. Similarly, $\mathbf{3} \boldsymbol{\beta}$ also generate a diglucoside (3ß-diglu) which was confirm by the HR-ESI-MS $m / z$ 767.3479 [M $+\mathrm{H}]^{+}$. Due to the small amount, it was not determined by NMR.

Using the same conditions as $\mathbf{2} \boldsymbol{\beta}$, we prepared $6.9 \mathrm{mg} \mathbf{3} \boldsymbol{\beta}$-glu with a conversion rate $50 \%$ ( $10 \mathrm{mg} 3 \boldsymbol{3}$ was served as substrate). The identification of the product $\mathbf{3} \beta$-glu was also confirmed by ${ }^{1} \mathrm{D}$ and ${ }^{2} \mathrm{D}$ NMR and HR-ESI-MS analysis. HR-ESI-MS showed a pseudo molecular ion $\mathrm{m} / \mathrm{z} 605.2996[\mathrm{M}+\mathrm{H}]^{+}$corresponding to a formula $\mathrm{C}_{32} \mathrm{H}_{44} \mathrm{O}_{11}$ (calcd for 605.2938) which was 162 unit larger than the parent compound $\mathbf{3} \boldsymbol{\beta}$. Similar to $\mathbf{2} \boldsymbol{\beta}$-glu, the chemical shifts of $\mathrm{C}-3$ and $\mathrm{H}-3$ of $3 \beta$-glu were shifted to downfield by $3.9 \mathrm{ppm}$ and $0.02 \mathrm{ppm}$, respectively, confirming the glycosylation site at $3-\mathrm{OH}$. The $\beta$-configuration was also confirmed by the large coupling constant of the anomeric proton $\left(\delta_{\mathrm{H}} 4.32, \mathrm{~d}, J=7.8 \mathrm{~Hz}\right)$. Accordingly, it was concluded that OleD (ASP) could catalyze the transformation of $\mathbf{3} \beta$ into $3 \beta$ glu.

\section{Glycosylation of $4 \beta$ and $4 \alpha$}

As compared to the three pairs of bufadienolides $1 \beta$ and $1 \alpha, 2 \beta$ and $2 \alpha, 3 \beta$ and $3 \alpha$, digitoxigenin ( $4 \beta)$ and uzarigenin $(4 \alpha)$ were two cardenolides with the same substitution pattern. The only difference between $\mathbf{4} \boldsymbol{\beta}$ and $\mathbf{4} \boldsymbol{\alpha}$ is the $\mathrm{A} / \mathrm{B}$ ring fusion modes,
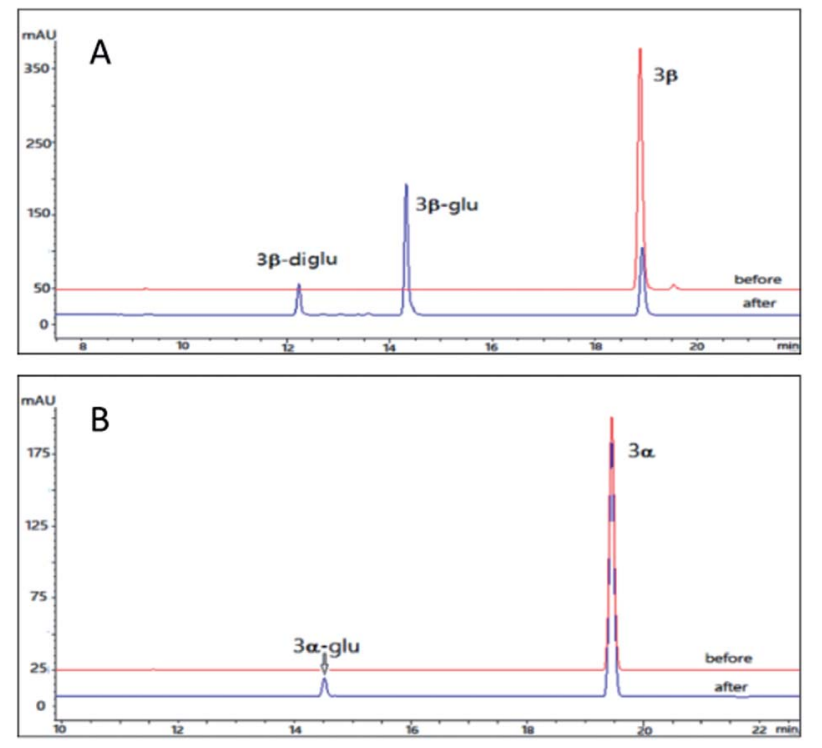

Fig. 4 HPLC chromatograms of the enzymatic reactions. (A) $3 \boldsymbol{\beta}$ without UDPG and OleD (ASP) (before); $3 \beta$ with UDPG and OleD (ASP) (after); (B) $3 \alpha$ without UDPG and OleD (ASP) (before); $3 \alpha$ with UDPG and OleD (ASP) (after). which are cis and trans, respectively. Compound $\mathbf{4} \boldsymbol{\beta}$ was the aglycone of digoxin, a commonly used cardiotonic drug. ${ }^{37}$ Recently, it is reported that introduction of a sugar unit at C-3 of cardenolides could improves NKA isoform selectivity $(\alpha 2 / \alpha 3$ over $\alpha 1){ }^{38,39}$ In order to compare the glycosylation profiles of $4 \beta$ and $\mathbf{4} \alpha$ with different $\mathrm{A} / \mathrm{B}$ ring fusion mode, the OleD (ASP) catalyzed bioconversion was carried out.

Using the same reaction conditions as described for the bufadienolides, OleD (ASP) catalyzed the generation of monoglucoside of $4 \beta$-glu with a conversion rate of $26 \%$; while the conversion rate for $4 \alpha$ is only $2 \%$ (Fig. 5). Thus the A/B ring fusion mode was also important for the conversion rate, and the lactone rings (either six-membered or five membered) at position $\mathrm{C}-17$ did not affect the biotransformation.

We prepared the monoglucoside of $\mathbf{4} \boldsymbol{\beta}$ ( $\mathbf{4 \beta}$-glu) for structural analysis. Compound $\mathbf{4 \beta}$-glu $(3.6 \mathrm{mg}$ ) was obtained by preparative HPLC with conversion rate $25 \%$ (10 $\mathrm{mg} \mathbf{4} \boldsymbol{\beta}$ of was used as the substrate). Similar to the bufadienolide glycosides $\mathbf{1} \beta$-glu, $2 \beta$-glu and $3 \beta$-glu, the monoglucoside structure of $4 \beta$-glu was confirmed by ${ }^{1} \mathrm{D}$ and ${ }^{2} \mathrm{D}$ NMR and HR-ESI-MS analysis $(\mathrm{m} / \mathrm{z}$ $537.8049[\mathrm{M}+\mathrm{H}]^{+} \mathrm{C}_{29} \mathrm{H}_{44} \mathrm{O}_{9}$, calcd for 537.8021). The glycosylation site was again determined at $3-\mathrm{OH}$ by comparison of chemical shifts of C-3 (downfield $3.9 \mathrm{ppm}$ ) and $\mathrm{H}-3$ (downfield $0.02 \mathrm{ppm}$ ) of $\boldsymbol{4} \boldsymbol{\beta}$-glu with those of the parent compound $\boldsymbol{4} \boldsymbol{\beta}$ and the $\beta$-configuration of the glycosidic bond was confirmed by the large coupling constant of the anomeric proton $\left(\delta_{\mathrm{H}} 4.32, \mathrm{~d}, J=\right.$ $7.8 \mathrm{~Hz}$ ). Accordingly, it was concluded that OleD (ASP) could catalyze the transformation of $\mathbf{4} \beta$ into $4 \beta$-glu.

\section{The determination of $\boldsymbol{K}_{\mathrm{m}}$ for the cardiotonic steroid epimers}

As we can see that the substrate structure and stereochemistry of cardiotonic steroid epimers significantly affect the final
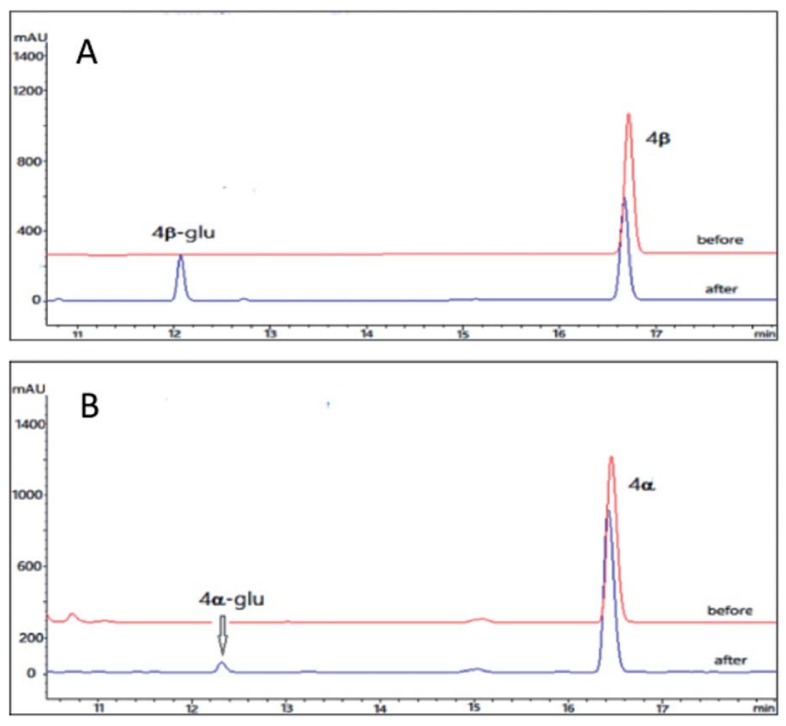

Fig. 5 HPLC chromatograms of the enzymatic reactions. (A) $4 \beta$ without UDPG and OleD (ASP) (before); $4 \beta$ with UDPG and OleD (ASP) (after); (B) $4 \alpha$ without UDPG and OleD (ASP) (before); $4 \alpha$ with UDPG and OleD (ASP) (after). 
Table 2 Conversion rate and $K_{\mathrm{m}}$

\begin{tabular}{lll}
\hline Compound & Conversion $^{a}(\%)$ & $K_{\mathrm{m}}(\mathrm{mM})$ \\
\hline $2 \boldsymbol{\beta}$ & 80 & $0.28+0.10$ \\
$2 \boldsymbol{\alpha}$ & 1 & $>100$ \\
$\mathbf{4} \boldsymbol{4}$ & 26 & $0.81+0.14$ \\
$\mathbf{4} \boldsymbol{}$ & 2 & $>100$ \\
${ }^{a}$ Conversion: calculated by the corresponding & HPLC \\
percentage. & &
\end{tabular}

glycosylation rate. In order to compare the dynamic process, $K_{\mathrm{m}}$ value was measured.

Epimers $2 \boldsymbol{\beta}$ and $2 \boldsymbol{\alpha}$ representing the high conversion bufadienolides and $\mathbf{4} \boldsymbol{\beta}$ and $\boldsymbol{4} \boldsymbol{\alpha}$ representing the cardenolides were chosen in this study. A series of concentrations of the substrates (0.01-1.2 mM) were incubated with the OleD (ASP) enzyme and UDPG, and the conversion rate was calculated by the corresponding HPLC peak area using the Agilent Chromatography Workstation Software. $K_{\mathrm{m}}$ value was determined based on the Michaelis-Menten equation. ${ }^{25}$ The result indicated that a high conversion rate corresponded to a low $K_{\mathrm{m}}$ value. Particularly,

A

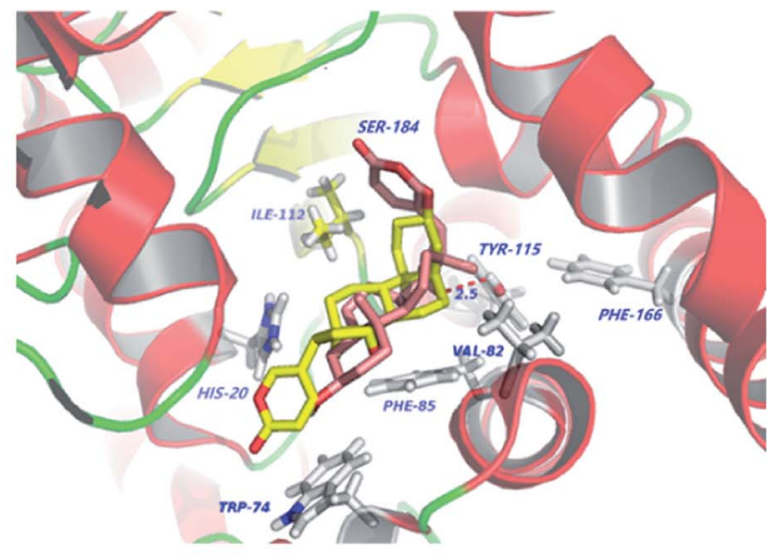

B

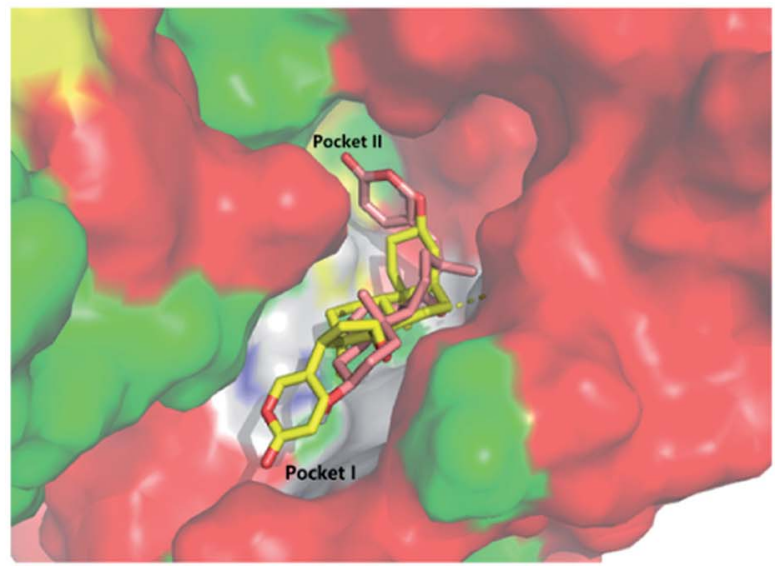

Fig. 6 (A) Selected docking poses of compound $2 \alpha$ (depicted in yellow) and $2 \boldsymbol{\beta}$ (depicted in magenta) into the substrate cavity of OleD (ASP). The two ligands are shown in stick representation. The receptors are shown in cartoon representation with cyan alpha helices, green beta sheets and magenta loops. (B) OleD (ASP) (surface)-ligand (stick) complex.
Table 3 Inhibition $\mathrm{Na}^{+}, \mathrm{K}^{+}$-ATPase activity

\begin{tabular}{llll}
\hline Compound & $\mathrm{IC}_{50}(\mu \mathrm{M})$ & Compound & $\mathrm{IC}_{50}(\mu \mathrm{M})$ \\
\hline $\mathbf{1} \boldsymbol{\beta}$ & $1.15 \pm 0.08$ & $\mathbf{1 \beta}$-glu & $0.32 \pm 0.03$ \\
$\mathbf{\beta}$ & $5.44 \pm 0.48$ & $\mathbf{2 \beta}$-glu & $1.94 \pm 0.10$ \\
$\mathbf{3}$ & $3.43 \pm 0.36$ & $\mathbf{3}$-glu & $1.22 \pm 0.10$ \\
$\mathbf{4} \boldsymbol{\beta}$ & $1.31 \pm 0.02$ & $\mathbf{4 \beta}$-glu & $0.78 \pm 0.05$
\end{tabular}

when the conversion rate is less than $2 \%, K_{\mathrm{m}}$ value is toward a large value more than $100 \mathrm{mM}$ (Table 2).

\section{Molecular modeling}

Molecular docking studies shed new light on the mechanism of stereoselective glycosylation of cardiotonic steroids derivatives. Similar for the $K_{\mathrm{m}}$ study, we selected the high conversion enantiomers $2 \alpha$ and $2 \boldsymbol{\beta}$ to explore the binding mode in the enzyme substrate complex. As can be seen from Fig. 6A, the $2 \mathrm{H}$ pyran-2-one ring of compound $2 \alpha$ penetrated deeply into the hydrophobic region I defined by His20, Phe85 and Trp74 residues. The epoxide contacted via van der Waals interactions with residues lle112 and Val82. In comparison to $2 \alpha$ binding to OleD (ASP), compound $2 \boldsymbol{\beta}$ showed an 'inverse' binding pose that C-3 aliphatic hydroxyl was placed in the hydrophobic pocket I and the $2 \mathrm{H}$-pyran-2-one moiety bound in a hydrophobic cavity II (lle112, Ser184, Fig. 6B). Moreover, the oxygen atom of epoxide group formed a hydrogen bond $(2.5 \AA)$ with critical residue Tyr115. It can be inferred from docking results that the filling of hydrophobic pocket II and interacted with residue Tyr115 may play an important role in the $O$-linked glycosylation reactions catalyzed by OleD (ASP) glycosyltransferase, since the conversion efficiency is $1 \%$ for $2 \alpha$ and $80 \%$ for $2 \beta$, respectively.

\section{Inhibition of NKA activity}

To explore the inhibitory activity of glycosylated products on NKA, the inhibition activity of CTS $(\mathbf{1} \boldsymbol{\beta}, \mathbf{2} \boldsymbol{\beta}, \mathbf{3} \boldsymbol{\beta}, \mathbf{4} \boldsymbol{\beta})$ and their

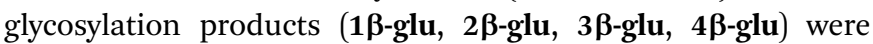
determined using previous reported method. ${ }^{11,27}$ As seen in Table 3, glycosylation products showed a stronger inhibitory activity for NKA than the corresponding aglycones.

\section{Conclusions}

In summary, this study demonstrated that the OleD-catalyze glycosylation of cardiotonic steroids are significantly influenced by the configuration at C-3 and the A/B fusion mode. $3 \beta$ $\mathrm{OH}$ and $\mathrm{A} / \mathrm{B}$ ring cis fusion are favoured by OleD (ASP), while an acetyl group at C-16 and lactone ring type at C-17 did not influence the biotransformation. A high conversion rate corresponded to a low $K_{\mathrm{m}}$ value. Molecular docking simulation showed that filling the hydrophobic pocket II and interaction with residue Tyr115 may play an important role in the glycosylation reactions catalyzed by OleD (ASP) glycosyltransferase. Furthermore, the glycosylation products showed a stronger inhibitory activity for NKA than the corresponding aglycones. This study provided the first stereoselective properties for OleD 
(ASP) catalyzed glycosylation. It is noteworthy that glycosyltransferase has been used for the glycosylation of a wide variety of natural products; ${ }^{\mathbf{4 0 , 4 1}}$ however, glycosyltransferase for the cardiotonic steroids is rare. Results of this study firstly revealed the stereo-selectivity of OleD-catalyzed glycosylation of cardiotonic steroids.

\section{Conflicts of interest}

There are no conflicts to declare.

\section{Acknowledgements}

This work was supported by the National Natural Science Foundation of China (No. 81573315), the Natural Science Foundation of Guangdong Province, China (No. 2015A030313313), the Guangzhou Industry-University Collaborative Innovation Major Projects, China (No. 201508030016) and the Natural Science Foundation of Hainan Province, China (No. 817307).

\section{Notes and references}

1 C. Hernández, C. Olano, C. Méndez and J. Salas, Gene, 1993, 134, 139-140.

2 C. Olano, A. M. Rodriguez, C. Méndez and J. A. Salas, Tetrahedron, 1995, 16, 333-343.

3 L. M. Quiros, I. Aguirrezabalaga, C. Olano, C. Méndez and J. A. Salas, Mol. Microbiol., 1998, 28, 1177-1185.

4 D. N. Bolam, S. Roberts, M. R. Proctor, J. P. Turkenburg, E. J. Dodson, C. Martinez-Fleites, M. Yang, B. G. Davis, G. J. Davies and H. J. Gilbert, Proc. Natl. Acad. Sci. U. S. A., 2007, 104, 5336-5341.

5 R. W. Gantt, R. D. Goff, G. J. Williams and J. S. Thorson, Angew. Chem., Int. Ed., 2008, 47, 8889-8892.

6 G. J. Williams, C. Zhang and J. S. Thorson, Nat. Chem. Biol., 2007, 3, 657-662.

7 M. Zhou, Y. Hou, A. Hamza, C.-G. Zhan, T. S. Bugni and J. S. Thorson, Org. Lett., 2012, 14, 5424-5427.

8 M. Zhou and J. S. Thorson, Org. Lett., 2011, 13, 2786-2788.

9 J. B. Lingrel, Annu. Rev. Physiol., 2010, 72, 395-412.

10 K. Haustein, Proceedings of the European Society of Toxicology Meeting, Kuopio, 1985, vol. 6, pp. 16-19.

11 D. A. Middleton, S. Rankin, M. Esmann and A. Watts, Proc. Natl. Acad. Sci. U. S. A., 2000, 97, 13602-13607.

12 T. Mijatovic, F. Dufrasne and R. Kiss, Curr. Med. Chem., 2012, 19, 627-646.

13 H. Y. Tian, L. Wang and G. A. O'Doherty, Expert Opin. Ther. Pat., 2012, 22, 587-605.

14 O. Aizman, P. Uhlén, M. Lal, H. Brismar and A. Aperia, Proc. Natl. Acad. Sci. U. S. A., 2001, 98, 13420-13424.

15 T. Akera and T. M. Brody, Life Sci., 1976, 18, 135-141.

16 G. Koren, C. Woodland and S. Ito, Vet. Hum. Toxicol., 1998, 40, 45-46.

17 R. A. Newman, P. Yang, A. D. Pawlus and K. I. Block, Mol. Interventions, 2008, 8, 36.
18 H. Gao, R. Popescu, B. Kopp and Z. Wang, Nat. Prod. Rep., 2011, 28, 953-969.

19 L. Krenn and B. Kopp, Phytochemistry, 1998, 48, 1-29.

20 P. S. Steyn and F. R. van Heerden, Nat. Prod. Rep., 1998, 15, 397-413.

21 H. Y. Tian, S. L. Luo, J. S. Liu, L. Wang, Y. Wang, D. M. Zhang, X. Q. Zhang, R. W. Jiang and W. C. Ye, J. Nat. Prod., 2013, 76, 1842-1847.

22 H. J. Tang, L. J. Ruan, H. Y. Tian, G. P. Liang, W. C. Ye, E. Hughes, M. Esmann, N. U. Fedosova, T. Y. Chung and J. T. Tzen, Sci. Rep., 2016, 6, 29155.

23 M. Ye, J. Han, D. An, G. Tu and D. Guo, Tetrahedron, 2005, 61, 8947-8955.

24 G. J. Williams and J. S. Thorson, Nat. Protoc., 2008, 3, 357362.

25 L. M. Quirós, R. J. Carbajo, A. F. Braña and J. A. Salas, J. Biol. Chem., 2000, 275, 11713-11720.

26 I. Klodos, M. Esmann and R. L. Post, Kidney Int., 2002, 62, 2097-2100.

27 M. Laursen, J. L. Gregersen, L. Yatime, P. Nissen and N. U. Fedosova, Proc. Natl. Acad. Sci. U. S. A., 2015, 112, 1755-1760.

28 R. R. Zhang, H. Y. Tian, Y. F. Tan, T. Y. Chung, X. H. Sun, X. Xia, W. C. Ye, D. A. Middleton, N. Fedosova, M. Esmann, J. T. C. Tzen and R. W. Jiang, Org. Biomol. Chem., 2014, 12, 8919-8929.

29 Y. H. Xu, J. Xu, Z. H. Chen, Z. J. Xie, R. W. Jiang and F. Feng, Chin. J. Struct. Chem., 2016, 35, 1024-1030.

30 R. J. Bick, B. J. Poindexter, R. R. Sweney and A. Dasgupta, Life Sci., 2002, 72, 699-709.

31 S. Q. Li, W. Schoner and Y. F. Fu, J. Biochem. Mol. Biol., 2002, 18, 250-253.

32 S. K. Wong, S. K. Tsui and S. K. Kwan, J. Pharm. Biomed. Anal., 2002, 30, 161-170.

33 Y. Kamano, A. Kotake, H. Hashima, M. Inoue, H. Morita, K. Takeya, H. Itokawa, N. Nandachi, T. Segawa and A. Yukita, Bioorg. Med. Chem., 1998, 6, 1103-1115.

34 T. Nogawa, Y. Kamano, A. Yamashita and G. R. Pettit, J. Nat. Prod., 2001, 64, 1148-1152.

35 Q. Chen, Research Methods in Pharmacology of Chinese Materia Medica, People's Medical Publishing House, 2011, pp. 330-331.

36 M. Ye, J. Dai, H. Guo, Y. Cui and D. Guo, Tetrahedron Lett., 2002, 43, 8535-8538.

37 S. R. Krim, R. P. Vivo, J. Perez, M. Inklab, T. Tenner and J. Hodgson, Am. J. Med. Sci., 2008, 336, 423-428.

38 A. Katz, Y. Lifshitz, E. Bab-Dinitz, E. Kapri-Pardes, R. Goldshleger, D. M. Tal and S. J. Karlish, J. Biol. Chem., 2010, 285, 19582-19592.

39 J. M. Langenhan, N. R. Peters, I. A. Guzei, F. M. Hoffmann and J. S. Thorson, Proc. Natl. Acad. Sci. U. S. A., 2005, 102, 12305-12310.

40 X. Z. He, W. S. Li, J. W. Blount and R. A. Dixon, Appl. Microbiol. Biotechnol., 2008, 80, 253-260.

41 E. K. Lim, D. A. Ashford and B. Hou, Biotechnol. Bioeng., 2004, 87, 623-631. 